\title{
Pierre Bourdieu, entre la autonomía y el compromiso.
}

\section{Pierre Bourdieu, between autonomy and commitment.}

Esta obra está bajo una Licencia Creative Commons Atribución 4.0 Internacional. DOI: $10.32870 /$ sincronia.axxii.n74.1b18

\author{
Osbaldo Amauri Gallegos de Dios \\ Universidad de Toulouse Jean Jaurès \\ (FRANCIA) \\ osbaldoamauri27@gmail.com
}

Recibido: $14 / 12 / 2017$

Revisado: 19/01/2018

Aprobado: 02/05/2018

\begin{abstract}
RESUMEN
En "Pierre Bourdieu, entre la autonomía y el compromiso" se analizan las diferentes posturas intelectuales de Pierre Bourdieu, lo que lo relaciona con la figura intelectual que cristalizó con el Affaire Dreyfus a finales del s. XIX, que se trata del escritor o artista en busca de verdad, justicia y razón. Así, Bourdieu se encuentra entre la búsqueda de autonomía y el compromiso académico.
\end{abstract}

Palabras clave: Pierre Bourdieu. Historia intelectual. Intelectual académico. Compromiso y autonomía.

\begin{abstract}
"Pierre Bourdieu, between autonomy and commitment" analyzes the different intellectual positions of Pierre Bourdieu, which are related with the beginning of the intellectual figure that started with Dreyfus' Affair at the end of XIX century, the writer or artist looking forward truth, justice and reason. Therefore Bourdieu can be related with autonomy and academic commitment.
\end{abstract}

Keywords: Pierre Bourdieu. Intellectual history. Academic intellectual. Commitment and autonomy.

Como es sabido, el Affaire Dreyfus fue un momento clave en la cristalización de la figura del intelectual en Francia. A finales de 1894, el capitán del ejército francés Alfred Dreyfus fue acusado injustamente de haber entregado a los alemanes documentos secretos, enjuiciado por un tribunal 
militar fue condenado a prisión perpetua por el delito de alta traición; ante esta injusticia el escritor Émile Zola publicó "J'accuse...!", un alegato a favor del capitán francés que cambió la opinión de varios escritores en Francia, movilizándolos a participar intelectualmente (Hourmant y Leclerc, 2012, pp. 9-11). Así, intelectual puede definirse como actor del debate público, ser cívico o "conciencia" de su tiempo (Altamirano, 2010, p. 9).

De igual manera, uno de los temas recurrentes sobre la historia intelectual es el silencio o desaparición de los intelectuales en Francia a finales del siglo XX. Alain Touraine (1999) afirma que el silencio relativo de los intelectuales en las últimas décadas se explica por el fin de un periodo histórico y está asociado al remplazo del análisis de los sistemas por la interpretación de los actores (pp. 152-154). François Dosse aborda la desaparición del intelectual comprometido, afirmando que Foucault ya había percibido esta mutación con su “intelectual específico” (Delacroix; Dosse; Garcia; \& Offenstadt, 2010, pp. 379). Por su parte, Yves Charles Zarka (2010) en La destitution des intellectuels explica lo que llama la "destitución de los intelectuales", porque en el tipo ideal de intelectual existen cuatro características: compromiso, autoridad, el riesgo de la verdad y estar tentado por la traición. "Destitución" significa que la función del intelectual ha perdido credibilidad y se ha vaciado de contenido, debido a que las condiciones de la toma de palabra en el espacio público han cambiado completamente. La lucha de los intelectuales contra el poder es importante, pero los medios de comunicación han sido esenciales en la destitución de los intelectuales (pp. 931).

Sin embargo, en el caso del francés Pierre Bourdieu (1930-2002) se puede encontrar esta figura del intelectual comprometido a finales del siglo XX; incluso Michel Winock (1999) en Le siècle des intellectuels sostiene que la secuencia de los intelectuales en Francia es: Sartre, Aron, Foucault y Bourdieu (pp. 760-761). Bourdieu fue un sociólogo francés, su sociología reprocha la dominación social y crea el "saber comprometido", es decir, un saber que milita para el establecimiento de la justicia y verdad en el mundo social, como lo establece Alain Accardo (2011) en Engagements. Chroniques \& autres textes. Bourdieu, por inclinación antropológica escogió situarse del lado de los 
dominados, del lado de la miseria del mundo. La sociología le sirve para luchar contra las formas de dominación, la ciencia social debe decir la verdad sobre la sociedad y las causas de sus inequidades, así como mostrar en qué puede ser útil para el combate emancipador (pp. 72-77). Por ende, puede observarse en el caso de Bourdieu, que a finales del siglo XX todavía puede encontrarse la figura del intelectual comprometido en Francia.

\section{Análisis de la figura intelectual}

Es claro que la obra de Pierre Bourdieu está vinculada con la sociología (Bourdieu, 1997), ya que es considerado uno de los sociólogos más importantes de la segunda mitad del siglo XX, sin embargo, existen entrevistas y obras de él, donde se encuentra expresado su pensamiento relacionado con la figura intelectual.

Como parte del contexto del silencio o desaparición de los intelectuales, en Francia a finales de los años setenta, Bourdieu, en sus análisis, fue crítico de ellos como se puede observar en la entrevista con François Hincker titulada “¿Los intelectuales están fuera del juego?” (“Les intellectuels sont-ils hors jeu ?") (1978) donde, Bourdieu afirma que la responsabilidad del intelectual se convierte en un hábito y tiende a reducir el pensamiento crítico en militantismo (1984, p. 66). Por otra parte, en la entrevista con Didier Eribon: “¿Cómo liberar a los intelectuales libres?" (“Comment libérer les intellectuels libres ?") (1980) Bourdieu señala que los intelectuales son poseedores de capital cultural y corresponden a una fracción dominada de la clase dominante; asimismo, explica algunas características del campo intelectual, como los reconocimientos y las gratificaciones imperceptibles que conllevan ciertas obligaciones y censuras sutiles (Bourdieu, 1984, p. 70).

Les règles de l'art. Genèse et structure du champ littéraire (1992) resulta una obra clave para entender la visión de la figura intelectual que tuvo Bourdieu. En el capítulo "L'invention de l'intellectuel" señala que la invención del intelectual se cumplió con Zola, pero no supuso la autonomía del campo intelectual. El intelectual se constituye como tal, interviniendo en política en 
nombre de la autonomía; se opone al escritor del siglo XVII que recibía prebendas del Estado y tenía una función subordinada. En el capítulo “L'intellectuel total et l'illusion de la toute-puissance de la pensée" afirma que Merleau- Ponty solo es un filósofo, Camus es un novelista, Blanchot es un crítico y Bataille un ensayista, por tal razón, no se pueden comparar con Sartre, quien representa al intelectual total y retomó la figura del intelectual que apareció con Zola (Bourdieu, 1998, pp. 216348).

Sobresale el capítulo "Post-scriptum: Pour un corporatisme de l'universel" porque aparece el concepto de intelectual colectivo de Bourdieu, quien afirma que está de moda hablar de la muerte de los intelectuales, es decir, el fin de uno de los contrapoderes críticos capaz de contraponerse al orden económico y político, por ende, es necesaria una acción colectiva de los intelectuales. Explica la relación entre el arte por el arte y el arte comprometido, para definir cuál es la acción colectiva de los intelectuales. La autoridad se reafirma con los actos políticos como el "Yo acuso" de Zola y las peticiones destinadas contra las injusticas; el compromiso genera una "política de la pureza" que se convierte en la antítesis de la "razón del Estado". Los intelectuales no se deben dejar dividir por los obstáculos, como el imperio de la economía sobre la investigación artística o científica, que se ejerce a través del control de los medios de producción y de difusión cultural. Por tal razón, resulta importante un grupo internacional para defender la autonomía de los propios intelectuales. La lucha debe ser colectiva para que sea eficaz y se debe reforzar la autonomía de los intelectuales combatiendo la relación con los diferentes poderes, sin excluir las burocracias del Estado. Para llegar al "intelectual colectivo" se debe renunciar al "intelectual orgánico" y comprometerse con la autonomía, lo que permite un corporativismo de lo universal (Bourdieu, 1998, pp. 545-558).

Por otra parte, en Intelectuales, política y poder Bourdieu (2000) establece que los intelectuales no son portavoces de lo universal pero frecuentemente tienen interés por el tema, sin embargo, ellos no tienen que ofrecer sus servicios sino imponer su visión del mundo social. Las tres posturas alrededor de las cuales se organizó el campo artístico e intelectual sobre todo entre 1830 y 1850, pero también a lo largo del siglo XIX, son: "el arte social”, "el arte por el arte" y "el arte 
burgués"; su significación estaba relacionada de forma directa o indirecta con estética y política. El "arte por el arte" se relaciona con artistas burgueses y se contraponen a los artistas "del pueblo". Una de las características de los miembros de la escuela del arte por el arte, es que cuando se observan sus biografías, se nota que se trata de burgueses descarriados, por lo tanto, es un arte para nada, distante de todo compromiso y busca glorificar los valores burgueses o instruir a las masas (2000, pp. 33-172).

Por lo tanto, en las entrevistas concedidas se puede observar una crítica de Bourdieu a los intelectuales, como parte de su contexto social que abordaba la desaparición de la figura intelectual en Francia alrededor de los años ochenta. Por el contrario, en las obras citadas de Bourdieu se encuentra su interés por la defensa de la autonomía en el campo intelectual, lo que lo conduce a abordar el arte social y la participación política de los pensadores.

\section{¿Intelectual colectivo vs. intelectual mediático?}

La idea del intelectual colectivo es una de las aportaciones de Bourdieu a la historia intelectual en el siglo XX. Retoma el modelo de intelectual establecido por Zola y su idea sobre el compromiso la relaciona con lo que llama "política real de la razón", que se trata de la participación activa en los trabajos del Comité internacional de apoyo a los intelectuales argelinos, como establece Pierre Mounier (2001) en Pierre Bourdieu Une introduction. El concepto de "intelectual colectivo" de Bourdieu surge en el post-scriptum de Las reglas del arte llamado "por un corporatismo de lo universal"; no es la primera vez que produce textos sobre el compromiso pero sobresale que éste fue incluido en una obra sociológica. Mounier se pregunta si el concepto de "intelectual colectivo" representa una contradicción debido a que no se respetan las especificidades del funcionamiento del campo intelectual autónomo (pp. 221-225).

El intelectual defendido por Bourdieu es aquel investigador que se apoya en el trabajo colectivo y en sus conocimientos; se opone al intelectual orgánico, aislado, sin compromiso ni raíces, como lo explica Jean-Philippe Cazier (2006) en Abécédaire de Pierre Bourdieu. El intelectual 
colectivo debe producir y difundir los instrumentos de defensa contra la dominación simbólica, es decir, la constitución de un contrapoder político. Esta concepción de intelectual se aleja del intelectual total que representa Sartre, comprometido en todos los frentes del pensamiento y la política. El intelectual colectivo corresponde a un agrupamiento de los "intelectuales específicos" en el sentido de Foucault, debido a que su compromiso está fundado en sus competencias científicas (pp. 101-102).

Bourdieu ha sido considerado como el arquetipo del intelectual crítico y una parte de su obra está dedicada a la sociología de los medios intelectuales, a la génesis y formación de los "campos intelectuales" en las sociedades occidentales; lo cual es explicado por Jean Baudouin en “Le 'dernier Bourdieu' ou la célébration paroxystique de l'intellectuel critique". Bourdieu presenta una sobrevaloración radical de la figura del intelectual crítico, y una desvalorización radical de la Política; la élite intelectual aspira a convertirse en un contra-poder. En "Por un corporativismo de lo universal" realizó una explicación socio-histórica del génesis del intelectual crítico y del campo intelectual; busca una visibilidad política e institucional a la "autonomización del campo intelectual", amenazado por la mercantilización de la educación y el aumento de poder de los “intelectuales mediáticos". De esta forma, Bourdieu, junto a Jacques Derrida, Édouard Glissant, Toni Morrisson, Susan Sontag y Salman Rushdie, intentó establecer un "Parlamento internacional de escritores" retomando el modelo de los enciclopedistas del Siglo de las Luces, lo cual lo aproxima al modelo de intelectual total de Sartre (Hourmant y Lecrerc, 2012, pp. 127-140).

A finales del siglo XX Bourdieu constituye la recapitulación elocuente de las prácticas intelectuales y aparece dentro del espacio público como "intelectual específico". Su trayectoria es un testimonio del paso del intelectual individual al múltiple, de lo singular a lo colectivo, como lo explica François Hourmant en "Les intellectuels et le pouvoir: des 'idiots utiles' aux prophètes d'institution". El trabajo de Bourdieu mezcla teoría y práctica alrededor de la idea del intelectual colectivo, que trata de tumbar las fronteras y favorecer las condiciones para la circulación de ideas a partir de redes internacionales (Hourmant y Lecrerc, 2012, pp. 7-22). 
Por otra parte, Bourdieu tuvo una lucha declarada contra los "intelectuales mediáticos", a quienes también llama "fast thinkers" o productores de fast food cultural, como lo señalan Patrick Champagne y Olivier Christin (2004) en Pierre Bourdieu. Mouvements d'une pensée. Bourdieu contribuyó a crear la figura del "intelectual investigador", el especialista en ciencias sociales que está mejor preparado para comprender el mundo social que el intelectual de Sartre, Zola o Gide, aunque ellos también tuvieron sus méritos. El intelectual-investigador no está aislado, participa en el universo de la ciencia y se apoya en el trabajo colectivo que produce la ciencia. En Règles de l'art de 1992, surgió el concepto de "intelectual colectivo" de Bourdieu, que es una síntesis del "intelectual total" encarnado por Sartre y el "intelectual específico" de Foucault. El intelectual en la época de las ciencias humanas no puede ser encarnado por un solo individuo, sino por un colectivo en el que cada quien contribuye con sus conocimientos (pp. 186-195).

A partir de los años noventa se observa en Bourdieu una crítica hacia los intelectuales mediáticos que deben su fama a los medios de comunicación, y la encarnación de este intelectual es el "nuevo filósofo" Bernard Henri-Lévy, como lo explica Nathalie Heinich (2007) en Pourquoi Bourdieu. Por esa época no solamente criticó a los periodistas y a quienes los manipulan, sino también recriminó a los medios de comunicación (pp. 90-93).

Por consiguiente, el francés busca la defensa de la autonomía del intelectual por medio de su "intelectual colectivo" que representa un contrapoder frente a la clase política. Sin embargo, está en contra de los "intelectuales mediáticos" que utilizan su fama y los medios de comunicación para lograr sus fines personales.

\section{Compromiso y autonomía}

Bourdieu actuó políticamente en algunas ocasiones, debido a que estuvo comprometido desde los años setenta apoyando a los sindicalistas frente a la represión del gobierno polaco, criticando los contenidos de la enseñanza en los liceos y contra la guerra del Golfo, como lo muestra Emmanuel Lemieux (2003) en Pouvoir intellectuel, Les nouveaux réseaux (pp. 436-438). Hasta la década de 
1990 Bourdieu comenzó a actuar políticamente y sus ideas se formaron de diferentes experiencias, como su experiencia en la guerra de Argelia, ya que de regreso en Francia, se convirtió en asistente de Raymond Aron en Les Temps modernes porque deseaba participar activamente en la vida intelectual, como establecen Patrick Champagne y Olivier Christin en Pierre Bourdieu. Mouvements d'une pensée (2004, pp. 188-190). En los años noventa, participó de diversas formas, ya que de 1989 a 1990 presidió una comisión sobre los contenidos de la enseñanza, en 1993 dirigió la obra colectiva La miseria del mundo, en 1995 apoyó a los huelguistas, en 1998 apoyó tanto a los desempleados como a los intelectuales argelinos y, en 1998 criticó el neoliberalismo, como lo explican Philippe Cabin et al en Pierre Bourdieu: son œuvre, son héritage (2008, pp. 13-17).

Dentro de este contexto, cabe resaltar la obra El sabio y la política. Ensayo sobre el terrorismo sociológico de Pierre Bourdieu (Le savant et la politique. Essai sur le terrorisme sociologique de Pierre Bourdieu) de Jeannine Verdès-Leroux, donde realiza una excelente investigación sobre las contradicciones en Bourdieu. Verdès-Leroux critica que Bourdieu evoca su pasado en un pueblo del sur de Francia como una enfermedad, lo que lo llevó a cambiar su acento cuando llegó a estudiar a París. Otra contradicción de Bourdieu es que afirma que la sociología debe estar al servicio de los dominados, pero su escritura es tan compleja que sólo puede ser entendida por las élites y no por la gente sin conocimientos específicos, por lo que los dominados resultan excluidos. La única forma que tiene de justificar su lenguaje artificial es que es necesario para explicar la complejidad de sus ideas. Bourdieu critica a los intelectuales, pero, a pesar de que no se considera uno de ellos, actúa como tal. Otras contradicciones son que reprochó a los intelectuales mediáticos pero apareció en un programa de televisión en FR3; asimismo, se burló de las intervenciones de los intelectuales pero también participó en la moda de firmar cartas abiertas o peticiones (Verdès-Leroux, 1998, pp. 10-22).

Sin haber admitido contradicción alguna, Bourdieu defendió la posición comprometida y la posición autónoma, dependiendo los contextos y los momentos de su carrera, como lo sostiene Nathalie Heinich (2007) en Pourquoi Bourdieu. En el francés se encuentra, por un lado, el 
compromiso de la persona y politización de la obra, por otro lado, sus posiciones explicitas e implícitas. Lo cual puede observarse en su apoyo en 1981 contra la dictadura en Polonia, su apoyo en 1986 a los estudiantes franceses, en 1993 su llamado en Estrasburgo para la creación de un "Parlamento de los intelectuales" (con Jaques Derrida, Édouard Glissant, Toni Morrison, Salman Rushdie, y Susan Sontag), en 1995 su apoyo a la huelga, en 1996 su petición en Le Monde para el reconocimiento de las parejas homosexuales, en 2000 su apoyo al movimiento antimundialización, y en 2001 su apoyo al movimiento antimundialización en Quebec. Por ende, Bourdieu pasó del antiestatismo en los años ochenta, al anti-neoliberalismo apoyado en la defensa del Estado en los años noventa, lo que se reflejó en sus obras y sus tomas de posición. Es de resaltar su capacidad para no comprometerse completamente, ya que durante décadas fue cercano a diferentes movimientos, como los movimientos de izquierda posteriores a 1968, el Partido socialista en poder en los años ochenta, o el movimiento altermundista en los años noventa (Heinich, 2007, pp. 68-102). Por ende, Bourdieu defendió la autonomía de los intelectuales y en diversas ocasiones participó políticamente, lo que muestra su compromiso con diferentes asuntos. No se consideraba un intelectual pero, a veces, actuaba como uno de ellos, sin embargo, para él no había ninguna contradicción en sus posturas.

\section{Conclusiones}

En conclusión, a pesar de que el silencio o desaparición de los intelectuales en Francia a finales del siglo XX, se convirtió en un tema significativo, Pierre Bourdieu, en ocasiones, se pudo asociar con la figura del intelectual comprometido. Cuando recriminaba a los "intelectuales mediáticos" por sus opiniones sin fundamento, los contraponía al especialista en ciencias sociales que estaba mejor preparado para comprender el mundo social. Así, podemos notar que en el compromiso político como objeto de la reflexión de Bourdieu, se observaba el compromiso académico y la defensa de la autonomía de los intelectuales, es decir, en sus teorías y entrevistas opinaba una cosa, pero en la práctica, a veces, hacía algo distinto. 


\section{Referencias:}

Accardo, A. (2011). Engagements. Chroniques \& autres textes (2000-2010). Marseille: Agone.

Altamirano, C. (editor del volumen) (2010). Historia de los intelectuales en América Latina II. Los avatares de la ciudad letrada en el siglo XX. Buenos Aires: Katz Editores.

Bourdieu, P. (1984). Questions de sociologie. Paris: Les éditions de minuit.

Bourdieu, P. (1997). Capital cultural, escuela y espacio social. México: Siglo XXI Editores.

Bourdieu, P. (1998). Les règles de l'art. Genèse et structure du champ littéraire. Paris: Éditions du Seuil.

Bourdieu, P. (2000). Intelectuales, política y poder. Buenos Aires: Editorial Universitaria de Buenos Aires.

Cabin, P. (et al). (2008). Pierre Bourdieu: son œuvre, son héritage. Auxerre: Sciences Humaines Éditions.

Cazier, J. P. (sous la direction de). (2006). Abécédaire de Pierre Bourdieu. Belgique: Les Éditions Sils Maria.

Delacroix, C.; Dosse, F.; Garcia, P. \& Offenstadt, N. (sous la direction de). (2010). Historiographies, concepts et débats. Paris: Gallimard.

Champagne, P.; Christin, O. (2004). Pierre Bourdieu. Mouvements d'une pensée. Paris: Bordas.

Hourmant, F.; Leclerc, A. (sous la direction de). (2012). Les intellectuels et le pouvoir. Déclinaisons et mutations. Rennes: Presses universitaires de Rennes.

Heinich, N. (2007). Pourquoi Bourdieu. Paris: Éditions Gallimard.

Lemieux, E. (2003). Pouvoir intellectuel. Les nouveaux réseaux. Paris: Denoël.

Mounier, P. (2001). Pierre Bourdieu. Une introduction. Paris: Pocket/ La Découverte.

Touraine, A. (1999). Comment sortir du libéralisme ? Paris: Fayard. 
Verdès-Leroux, J. (1998). Le savant et la politique. Essai sur le terrorisme sociologique de Pierre Bourdieu. Paris: Bernard Grasset.

Winock, M. (1999). Le siècle des intellectuels. Paris: Éditions du Seuil.

Zarka, Y. C. (2010). La destitution des intellectuels et autres réflexions intempestives. Paris: Presses Universitaires de France. 